\title{
Portland Cement Hydration Behavior at Low Temperatures: Views from Calculation and Experimental Study
}

\author{
Zhuangzhuang Liu, ${ }^{1,2}$ Wenxiu Jiao, ${ }^{2}$ Aimin Sha, ${ }^{1,2}$ Jie Gao, ${ }^{2}$ \\ Zhenqiang Han, ${ }^{2}$ and Wei $\mathrm{Xu}^{2}$ \\ ${ }^{1}$ Key Laboratory for Special Area Highway Engineering, Ministry of Education, Xian, China \\ ${ }^{2}$ School of Highway, Chang'an University, Xian, China \\ Correspondence should be addressed to Zhuangzhuang Liu; liuzhuangzhuang1986@gmail.com
}

Received 14 April 2017; Revised 6 July 2017; Accepted 1 August 2017; Published 12 September 2017

Academic Editor: Aboelkasim Diab

Copyright ( 2017 Zhuangzhuang Liu et al. This is an open access article distributed under the Creative Commons Attribution License, which permits unrestricted use, distribution, and reproduction in any medium, provided the original work is properly cited.

\begin{abstract}
Environmental condition affects the property of construction materials. This study gives an initial understanding of Portland cement hydration under low temperatures from the views of laboratory experiments (including electrical resistivity, degree of hydration $(\mathrm{DoH})$, and maturity) as well as thermodynamic calculation. The hydrates of Portland cement at the given period were detected with X-ray diffraction (XRD), and their microstructure was observed by scanning electron microscope (SEM). Experiment result (i.e., DoH and electrical resistivity) indicated that the hydration of Portland cement was delayed by low temperature without hydration stopping at $-5^{\circ} \mathrm{C}$. Based on a basic kinetics model, the thermodynamic calculation predicted that the final hydrate differs in dependence on environmental temperatures. The mechanical behavior trend of Portland cement paste affected by low temperatures potentially is linked to the appearing of aluminate compounds and reduction of portlandite.
\end{abstract}

\section{Introduction}

Temperature affects the performances of Portland cement which is the most widely used materials in infrastructure constructions [1]. Meanwhile, the matrix of cement binder acts a greatly important role in Portland cement-based composites (i.e., pastes, mortars, concrete, stabilized stones, and treated soils). The performance of hardened Portland cement (e.g., mechanical behavior, and durability) is linked tightly with early age chemical hydration and hardening, while the relationships between hydration processes, hydrates produced, microstructures, and mechanical behaviors have been proved in previous studies [2-5]. In service life of infrastructures, cement-based materials have to be faced with severe environmental conditions, such as super-low temperatures [6-8]. In these conditions mechanical behaviors (e.g., compressive strength, flexural strength, elastic modulus, and Poisson ratio) of hardened Portland cement concrete will be enhanced by the super-low temperature, for example, $-70 \sim$ $-10^{\circ} \mathrm{C}[7]$.
Differently, if cement-based materials (pastes, mortars, concrete, etc.) are experienced with low temperature, especially negative temperature $\left(<0^{\circ} \mathrm{C}\right)$ during initial hydration stage, cement hydration will be greatly affected [9-11]. In this case, the hydrated products, phase conversion, for example, from ettringite (AFt) to monosulfate $(\mathrm{AFm})$, and pores solution will be affected by low temperatures [5, 12]. In some limited conditions, the matrix would be even damaged. Thus, strategies in early ages should be applied to avoid the damages in matrix under cold weathers $[13,14]$. To this end, a lot of studies were conducted to learn the Portland cement hydration under low temperatures [10,11,15-18], even though there is still lack of understanding in depth to the low temperature effects on cement hydration and hardening characteristics.

Better understanding of Portland cement hydration can absolutely promote the performance of cement composites under low temperatures, especially for the application at cold climates. Thus, this study aims to investigate the hydration 
process of Portland cement, including hydrates, microstructures, and mechanical behavior evolution. To further understand the low temperature effects on hydration process, thermodynamic approach is also employed to calculate the hydrates of Portland cement paste. Basically, this research provides a basic knowledge about the hydration process of Portland cement under low temperatures as a part of a systematic study.

\section{Experimental Program}

2.1. Raw Materials. A typical commercial ordinary Portland cement (OPC, produced by Jidong Cement Plant, Xi'an, China) was used in this study with oxide components detailed in Table 1 (PO42.5). What should be noted is that the oxide components measured by XRF here did not reflect the real component in Portland cement due to $5 \sim 10 \%$ filler replacement in clinkers. The mineral phases in OPC (via XRD) and the particle size distribution are shown in Figure 1. The technical properties of PO42.5 used in this study (provided by the producer) are as follows: specific surface area (Blaine) $=$ $360 \mathrm{~m}^{2} / \mathrm{kg}$, density $=3.02 \mathrm{~g} / \mathrm{cm}^{3}$, initial setting time $=2.8 \mathrm{hrs}$, and final setting time $=4.7 \mathrm{hrs}$.

\subsection{Methods and Instruments}

2.2.1. Laboratory Experiments. The cement pastes were mixed according to ASTM C305-14 [20] and then were removed into molds $(40 \times 40 \times 160 \mathrm{~mm})$ or plastic containers; afterward, they were cured in chambers under $-5^{\circ} \mathrm{C}, 0^{\circ} \mathrm{C}, 5^{\circ} \mathrm{C}, 8^{\circ} \mathrm{C}$, and $20^{\circ} \mathrm{C}(\mathrm{RH}=90 \%)$. It should be noted that before mixing raw materials (i.e., Portland cement and water), molds and bowls should be precooled in chambers consistent with their following curing temperature. For example, if the paste sample is going to be cured at $0^{\circ} \mathrm{C}$, the water, cement, bowls, and molds should be precooled under $0^{\circ} \mathrm{C}$ for two hours until their surface reaches $0^{\circ} \mathrm{C}$. In experimental study, the water-cement $(\mathrm{w} / \mathrm{c})$ ratio of prisms samples for strength measurement was set as 0.45 , while the w/c of the paste stored in sealed plastic containers was given as 0.5 for complete reaction.

The pastes in container were treated following the solvent exchange method (with isopropanol) [21] and then were measured with XRD (Bruker, D8 Advanced, $\mathrm{Cu}-\mathrm{K} \alpha$ ) and SEM (Hitachi, S4800).

In order to describe the hydration process of Portland cement pastes, degree of hydration $(\mathrm{DoH})$, maturity, and electrical resistivity were measured in this research. The DoH of Portland cement pastes was determined as (1) based on Powers model [22].

$$
\mathrm{DoH}=\frac{m_{105}-m_{950}}{0.25 \times m_{105}}
$$

where DoH is the degree of hydration (\% by weight), $m_{105}$ is the initial mass of sample pretreated in muffle furnace (6 hours) at $105^{\circ} \mathrm{C}$, and $m_{950}$ is the final mass of sample heated at $950^{\circ} \mathrm{C}$.

Electrical resistivity of cement paste could be utilized to analyze the cement hydration process well [19]. Thus, the resistivity curve during initial Portland cement hydration was detected via CCR-II (produced by BC Tech, Shenzhen City, China). The equipment and sample were shown in Figure 2. To prevent moisture evaporation and temperature fluctuation, a plastic cover was set on the test-board, while the temperature was controlled by air-conditioner (general temperature) or chamber (lower temperatures).

The maturity was calculated according to the following equation $[10,11,23]$ :

$$
M=\sum_{0}^{t}\left(T_{c}-T_{0}\right) \cdot \Delta t,
$$

where $M$ is the maturity of Portland cement paste, $T_{c}$ is the sample temperature $\left({ }^{\circ} \mathrm{C}\right)$ measured by CCR-II (detailed above) or curing temperature $\left(-5^{\circ} \mathrm{C}, 0^{\circ} \mathrm{C}, 5^{\circ} \mathrm{C}, 8^{\circ} \mathrm{C}\right.$, and $\left.20^{\circ} \mathrm{C}\right)$, $T_{0}$ is the base temperature $\left(-10^{\circ} \mathrm{C}\right.$, generally), and $\Delta t$ is the time interval during curing stage $(\mathrm{h})$.

2.2.2. Thermodynamic Calculation. Gibbs free-energy minimization criteria were used to calculate equilibrium phase assemblages and ionic speciation of chemical systems, such as the Portland cement paste. The modeling and software were detailed in our previous study [18], in which GEMSPSI (software) and CEMDATA7.1 (database) were employed to calculate the hydrates of OPC. What should be noted is that in this study a basic kinetic function [24] of Portland cement hydration was modified by a solution equilibrium constant $[18,25]$. In the thermodynamic simulation, input data included the following: $\mathrm{C}_{2} \mathrm{~S}=11.1 \mathrm{~g} / 100 \mathrm{~g}, \mathrm{C}_{3} \mathrm{~S}=62.9 \mathrm{~g} / 100 \mathrm{~g}$, $\mathrm{C}_{3} \mathrm{~A}=6.0 \mathrm{~g} / 100 \mathrm{~g}, \mathrm{C}_{4} \mathrm{AF}=11.5 \mathrm{~g} / 100 \mathrm{~g}$, gypsum $=4.6 \mathrm{~g} / 100 \mathrm{~g}$, $\mathrm{K}_{2} \mathrm{O}=1.1 \mathrm{~g} / 100 \mathrm{~g}$, and $\mathrm{Na}_{2} \mathrm{O}=0.3 \mathrm{~g} / 100 \mathrm{~g}$. Also, 10000 days were adapted as the final hydration term in the simulation. The theoretical calculation from thermodynamics could provide deeper explanation to mechanical behaviors.

\section{Results and Discussion}

3.1. Electrical Resistance at Early Ages. Figure 3 shows the resistivity curve of Portland cement during hydration. After being mixed with water the ions (e.g., $\mathrm{Ca}^{2+}, \mathrm{K}^{+}, \mathrm{Na}^{+}, \mathrm{OH}^{-}$, and $\mathrm{SO}_{4}{ }^{2-}$ ) dissolved into the water forming an electrolytical solution [26], and then the hydrates would expend the ions in solution or occupy the space of solution; thus the resistivity of paste could be utilized to observe the hydration stages during hydration. It was reported that the cement hydration could be divided into five stages: (1) dissolution stage; (2) dynamic balance stage; (3) setting stage; (4) hardening stage; and (5) hardening deceleration stage [19]. Based on the previous study [19], the curve of resistivity and differential resistivity could point out the initial setting and final setting time well. In Figure 3, the normalized data of resistivity shows an obvious bottom which matches the start of initial setting. Also, the starting position of the hardening deceleration stage could be confirmed at the top of differential electrical resistivity curve. The curves in Figure 3 show that the temperature data and resistivity data were in a good agreement with each other. Therefore, the temperature data in CCR-II measurement can also be considered to describe the cement hydration. This 
TABLE 1: Oxide composition of Portland cement used in this study ${ }^{*}$.

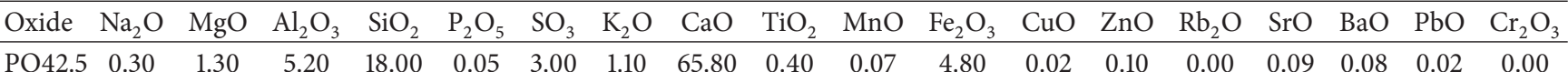

* Data collected by X-ray fluorescence (XRF).

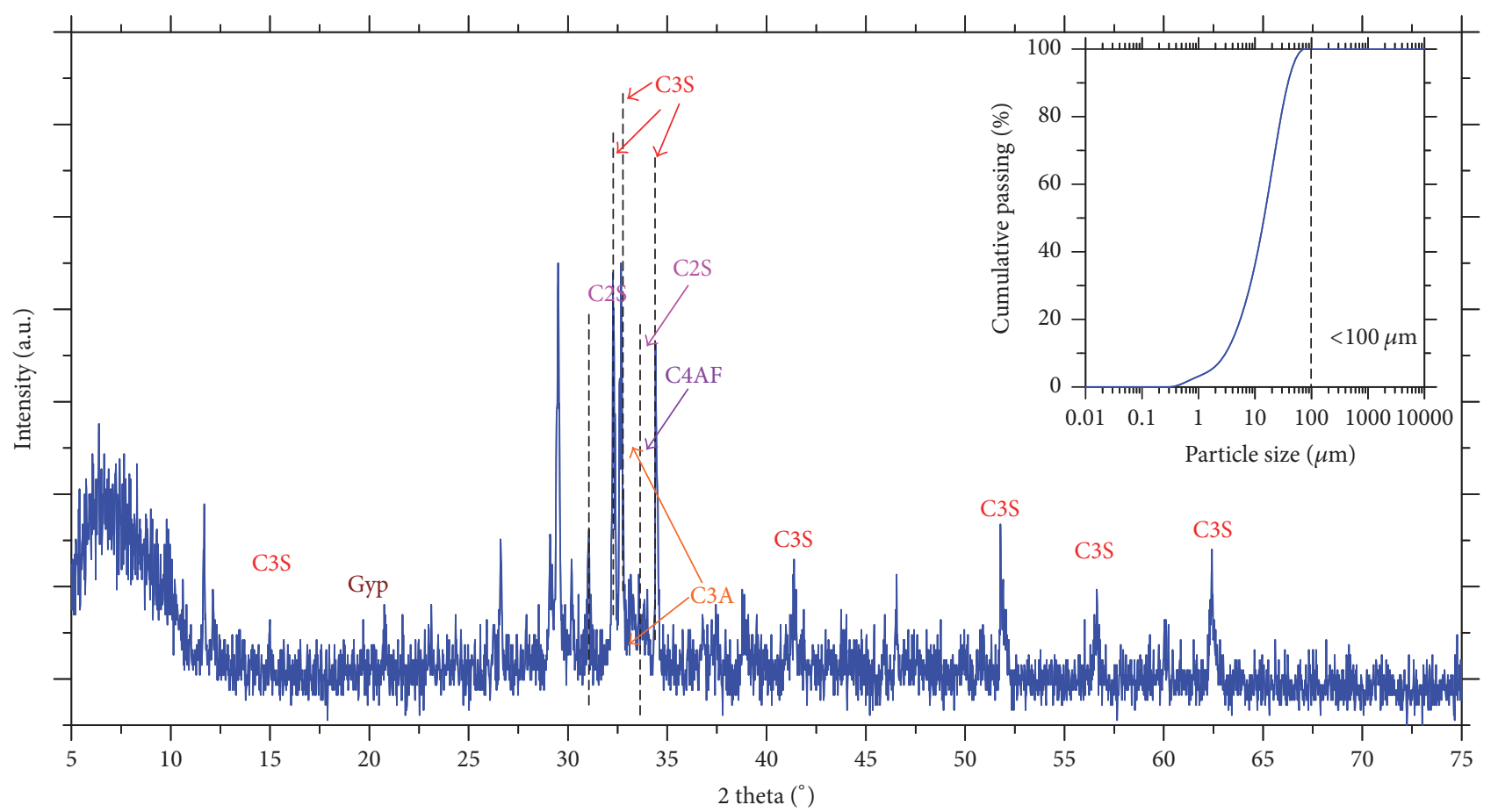

Figure 1: Particle size and minerals phases of raw materials.

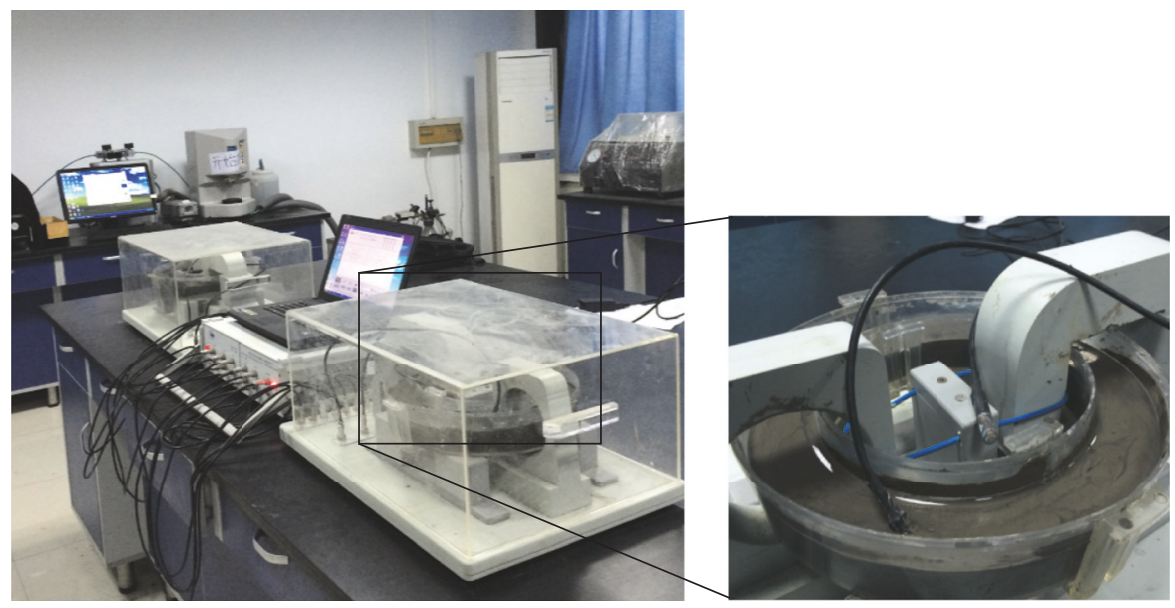

(a)

(b)

FIgURE 2: Electrical resistivity measurement: device and sample setting. 


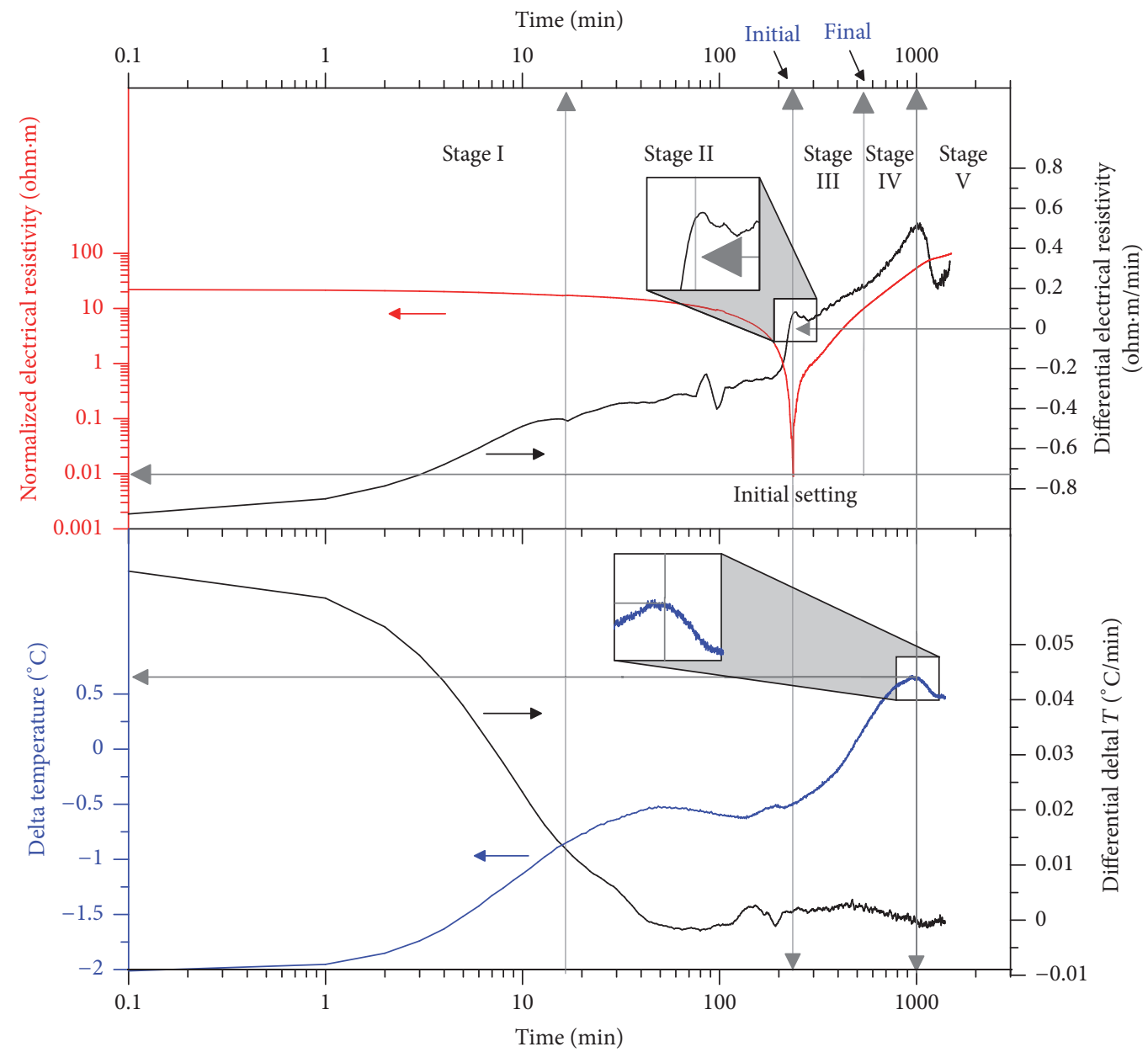

FIGURE 3: Electrical resistivity of Portland cement during hydration: five stages of Portland cement hydration according to [19].

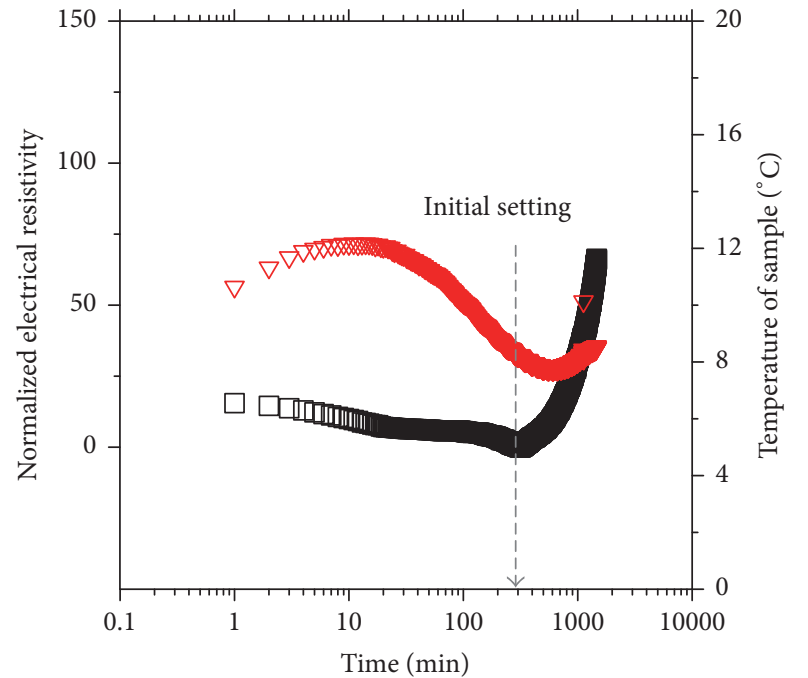

OPC cured at $8^{\circ} \mathrm{C}$

$\square$ Normalized ER

$\nabla$ Temperature

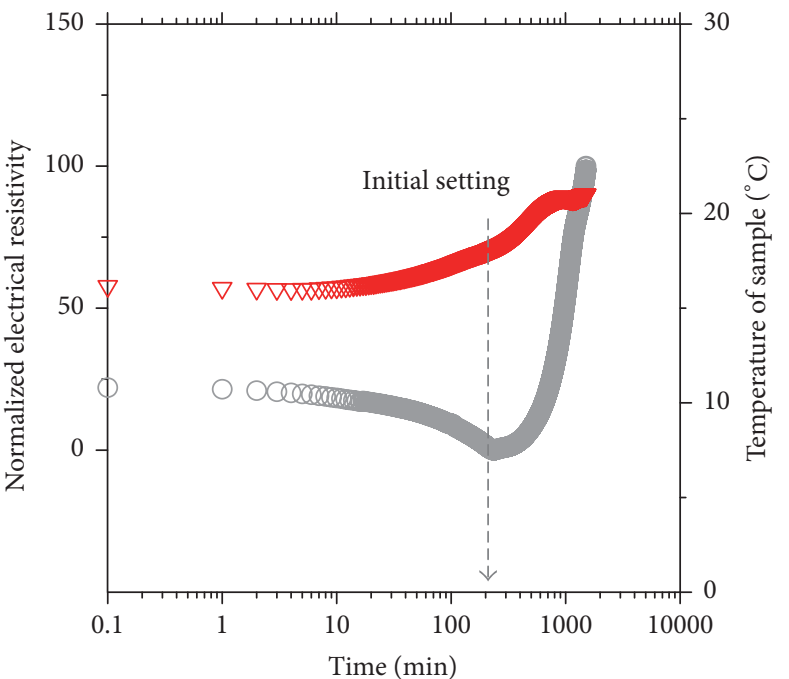

OPC cured at room temperature

O Normalized ER

$\nabla$ Temperature

(a) $8^{\circ} \mathrm{C}$

(b) Room temperature

FIGURE 4: Sample temperature variation. 


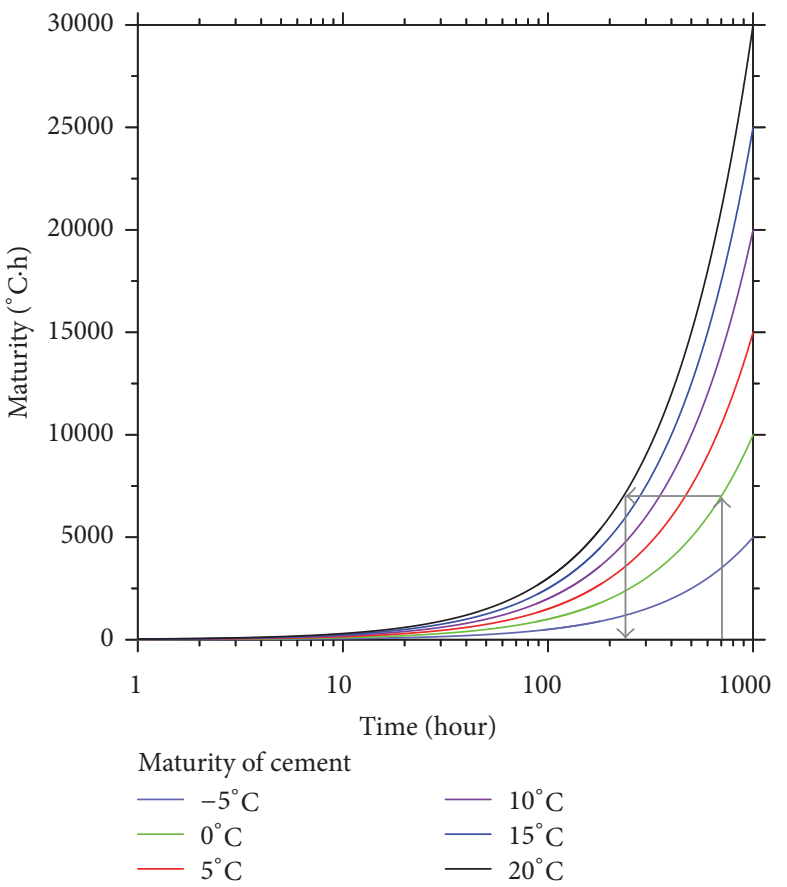

(a) Environmental temperature

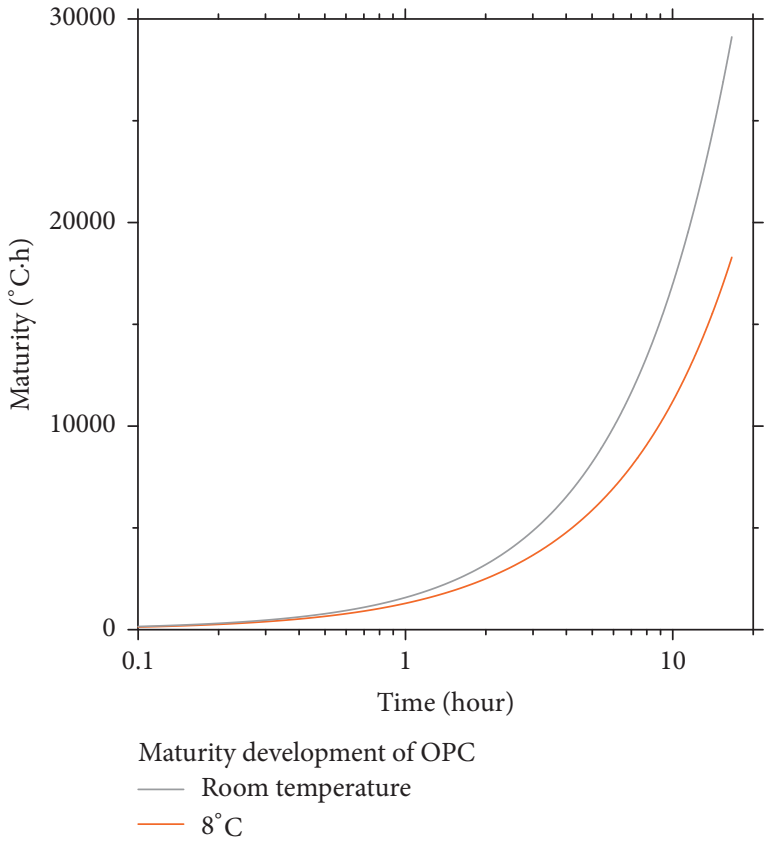

(b) Sample temperature

FIGURE 5: Maturity development of cement paste.

conclusion is the basis to adapt the temperature data of sample in maturity calculation below.

Figure 4 presents the normalized resistivity data of Portland cement pastes under $8^{\circ} \mathrm{C}$ (Figure $4(\mathrm{a})$ ) and $20^{\circ} \mathrm{C}$ (Figure 4(b)). Two important characteristics could be noticed in the curves: (i) low temperature $\left(8^{\circ} \mathrm{C}\right)$ delays the bottom (initial setting time position) of normalized resistivity curve; (ii) the initial plot of normalized resistivity curve at low temperature $\left(8^{\circ} \mathrm{C}\right)$ was lower than that at general condition $\left(20^{\circ} \mathrm{C}\right)$. They are due to the chemical reaction rate reduced by low temperatures.

3.2. Sample Temperature and Maturity Development. The temperature changing was also recorded by sensors (seeing Figure 2(b)) as detailed in Figure 4. In lower curing temperature $\left(8^{\circ} \mathrm{C}\right)$, sample temperature increased due to the chemical reaction in paste and then decreased caused by cooler environment outside. In room temperature the sample temperature kept increasing, where sample temperature showed less relationship with electrical resistivity of paste.

Figure 5 shows the maturity calculated based on the curing/sample temperature via (2). Figure 5(a) is the ideal maturity curve calculated by curing temperature, while Figure 5(b) showed the maturity calculated by sample temperature (see (2)). As believed, the mechanical behaviors of cement-based composites have great relationships with maturity [10]. Taken in this sense, Figure 5 could act as an evidence of the strength delaying in previous studies $[17,18]$.

3.3. Degree of Hydration. Degree of hydration (DoH) responds to the reaction process of cement paste; hence the $\mathrm{DoH}$ of cement paste cured in lower temperatures was measured based on Powers' model and shown in Figure 6. Beyond the curing time, the $\mathrm{DoH}$ of cement with the same curing temperature increased, while higher hydration rate was obtained with higher temperatures. Take $-5^{\circ} \mathrm{C}$, for instance, its $\mathrm{DoH}$ beyond $90 \mathrm{~d}$ was $63.2 \%$, much lower than that of a general condition $\left(91.9 \%\right.$ at $\left.20^{\circ} \mathrm{C}\right)$. This result agreed with the conclusion of FHWA's report [23]. Meanwhile, the experiment indicates the Portland cement can still hydrate at $-5^{\circ} \mathrm{C}$; for example, the DoHs of OPC at $-5^{\circ} \mathrm{C}$ were $16.7 \%$, $25.5 \%, 47.4 \%, 55.3 \%, 61.9 \%$, and $63.2 \%$ beyond $1,3,7,28$, 60 , and 90 days, respectively. This result explains the slow strength achievement of cement pastes exposed in negative temperatures.

3.4. XRD Analysis. Figure 7 shows the XRD analysis of Portland cement hydrates under different temperatures $(1 \mathrm{~d})$. It can be seen that the portlandite $\left(\mathrm{Ca}(\mathrm{OH})_{2}\right)$ peak differs by curing temperature. To $-5^{\circ} \mathrm{C}$, there was no obvious portlandite peak, and the mineral phase can be observed clearly (1d). There were no AFt peaks at 1 day for the pastes cured under $-5,0,5$, and $8^{\circ} \mathrm{C}$.

3.5. SEM. The microstructure of hydrated paste was arranged in Figure 8. According to the $\mathrm{DoH}$ above, less Portland cement hydrated under $-5^{\circ} \mathrm{C}$; thus the separated particles in Figure 8(a) could be explained in which the solid did not bind with others. To other temperatures, the pastes hardening was related to the curing temperature. If focused on the hydrates, there were some separated particles in Figure $8(\mathrm{~b})\left(0^{\circ} \mathrm{C}\right)$, while there were few unhydrated particles in Figure 8(c) 


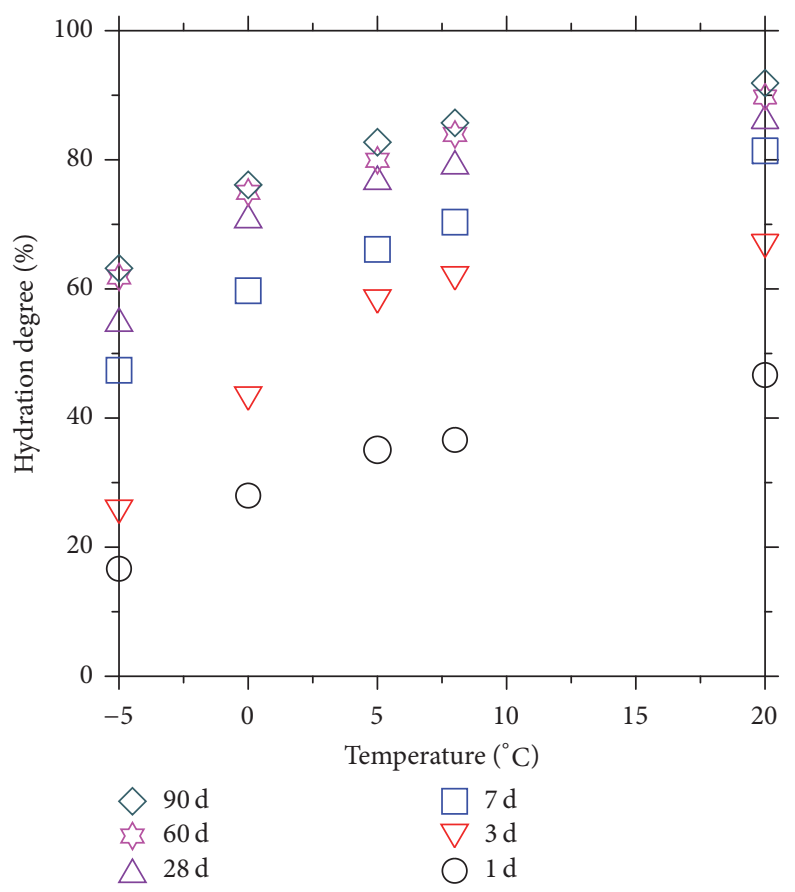

FIGURE 6: Degree of hydration development over curing temperature variation.

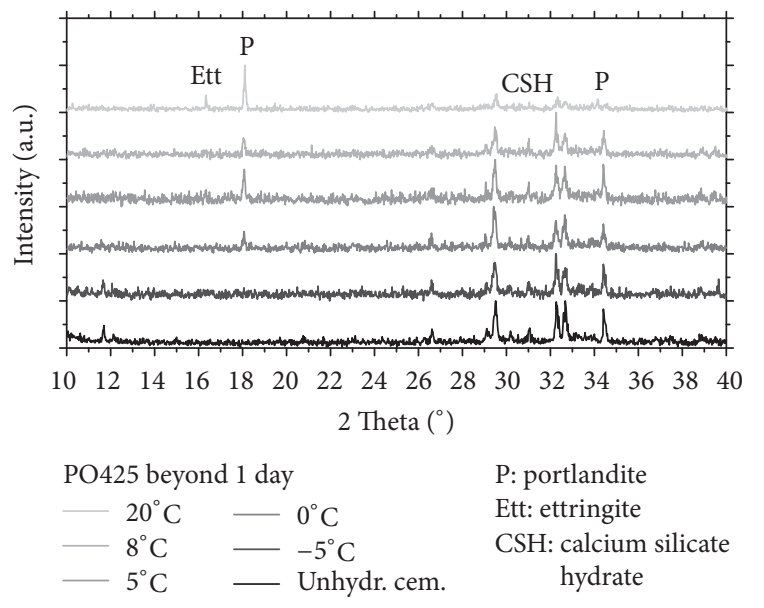

FIGURE 7: XRD result of OPC responded to curing temperature (1 day).

$\left(5^{\circ} \mathrm{C}\right)$. If the curing temperature was higher than $8^{\circ} \mathrm{C}$, less unhydrated particles could be observed in SEM images (see Figures $8(\mathrm{~d})$ and $8(\mathrm{e})$ ). Considering the $\mathrm{DoH}(47.4 \%)$ of Portland cement cured at $-5^{\circ} \mathrm{C}$ in $7 \mathrm{~d}$, the cement should produce some hydrates to bind the particles in paste; however, the $\mathrm{DoH}$ of this sample $\left(-5^{\circ} \mathrm{C}, 7 \mathrm{~d}\right)$ was just similar to the one cured at $20^{\circ} \mathrm{C}$ in $1 \mathrm{~d}(46.7 \%$, see Figure 4$)$. At this $\mathrm{DoH}$ level, particles in paste did not react to bind with others. Actually, the Portland cement just finished phase-boundary reaction and reached diffusion controlled hydration [27] at this DoH level while the spaces between particles were not filled by hydrates. With the DoH increasing (i.e., related with temperature), spaces between hydrates would be filled and then bind with each other. Here, another reason should not be ignored that the particles in cement paste were moved and separated by ice formed at $-5^{\circ} \mathrm{C}$ (negative temperatures).

\section{Thermodynamic Calculation of Portland Cement Hydration at Low Temperature}

4.1. Portland Cement Hydrates over Curing Time. Thermodynamic calculation of Portland cement hydration has been proved by a number of studies. Figure 9 shows the hydrates evolution at $20^{\circ} \mathrm{C}$ based on the thermodynamic simulation. As shown in the figure, the hydrates increased over curing time. The Aft was converted into $\mathrm{AFm}$ at $1 \mathrm{~d}$ and then disappeared at $2 \mathrm{~d}$, while the $\mathrm{C}_{3} \mathrm{AH}_{6}$ phase appeared after $3 \mathrm{~d}$. This calculation result was proved by our experimental data as the low temperature effects have been reported previously. The final hydrates will be potentially changed within $0 \sim 10^{\circ} \mathrm{C}$. Mineral phase variation can be seen in Figure 10.

4.2. Relationships between Strength, Hydrates, and Temperature. The mechanical behavior of cement paste is linked significantly to its hydrates. For instance, the relationship between mechanical behavior and CSH content has been proved in our previous study [17]. Figure 10 shows the relationships between curing temperature, compressive strength, and hydrates volume fraction. The hydrate fractions were collected from thermodynamic calculation (age $=10000 \mathrm{~d}$ ).

The strength was measured under $0,5,8$, and $20^{\circ} \mathrm{C}$ and beyond $3 \mathrm{~d}, 7 \mathrm{~d}$, and $28 \mathrm{~d}$. It can be seen that (1) the content of CSH was not significantly affected by curing temperature beyond long ages; (2) the volume fractions of AFt, AFm, and portlandite were changed with curing temperature; (3) 


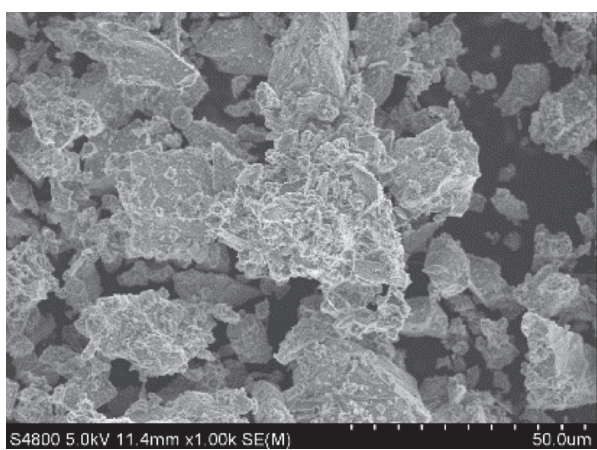

(a) $-5^{\circ} \mathrm{C}$

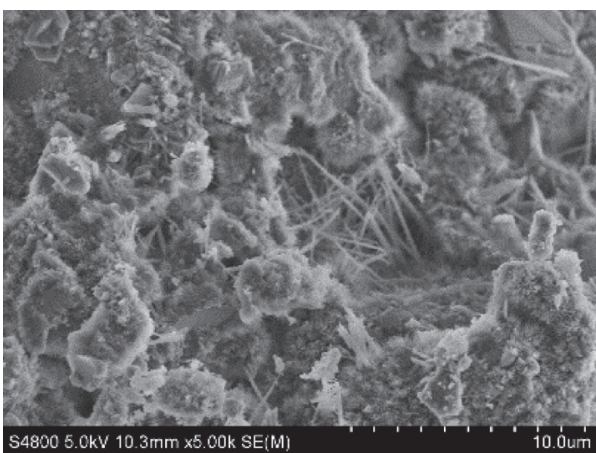

(c) $5^{\circ} \mathrm{C}$

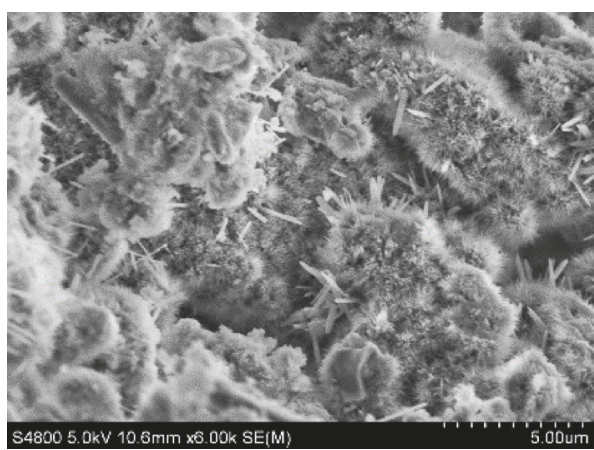

(b) $0^{\circ} \mathrm{C}$

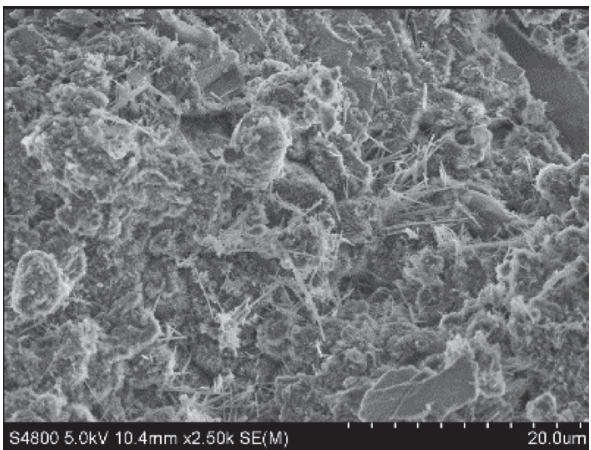

(d) $8^{\circ} \mathrm{C}$

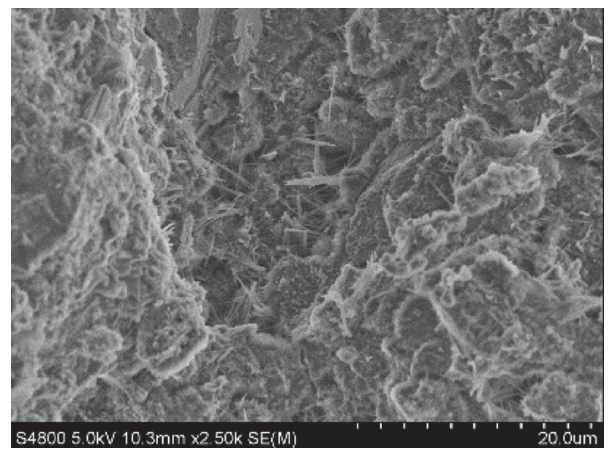

(e) $20^{\circ} \mathrm{C}$

FIgURE 8: SEM images of solid cement pastes cured under low temperatures (7d).

the long-term (28 d) strength showed few relationships with $\mathrm{CSH}$ content but was linked greatly with AFt, AFm, and portlandite, at the point of $10^{\circ} \mathrm{C}$. With the reduction of $\mathrm{CH}$, the compressive strength was increased. Also, the AFm might benefit the mechanical strength in Portland cement at low temperatures.

This finding was very interesting because we always thought that the mechanical behaviors were linked to the $\mathrm{CSH}$ volume fraction tightly, but in this study on the premise of different early curing temperatures we found that the mechanical strength changing had no relationship with the $\mathrm{CSH}$ content (strength differs with a similar/the same CSH volume fraction) but is linked significantly with the produced aluminate hydrates and portlandite. What should be noted is that the above conclusion may not be $100 \%$ right, but we would like to consider that the temperature effects on early mechanical behavior should have deeper explanations, thermodynamically. However, these deductions need more evidence in the future.

\section{Summary and Conclusions}

The Portland cement (PO42.5) hydration characteristics at early ages including electrical resistance, temperature evolution, degree of hydration, and phase evolution were observed in laboratory under the curing temperature of $-5,0,5$, 8 , and $20^{\circ} \mathrm{C}$. Thermodynamic calculation based on GEMSPSI software was also utilized to explain and verify the experimental results. Conclusions can be drawn as follows:

(1) Low temperatures $\left(-5,0,5\right.$, and $\left.8^{\circ} \mathrm{C}\right)$ reduced the hydration rate but did not terminate the hydrate reaction; also, the hydration process remains as generate 


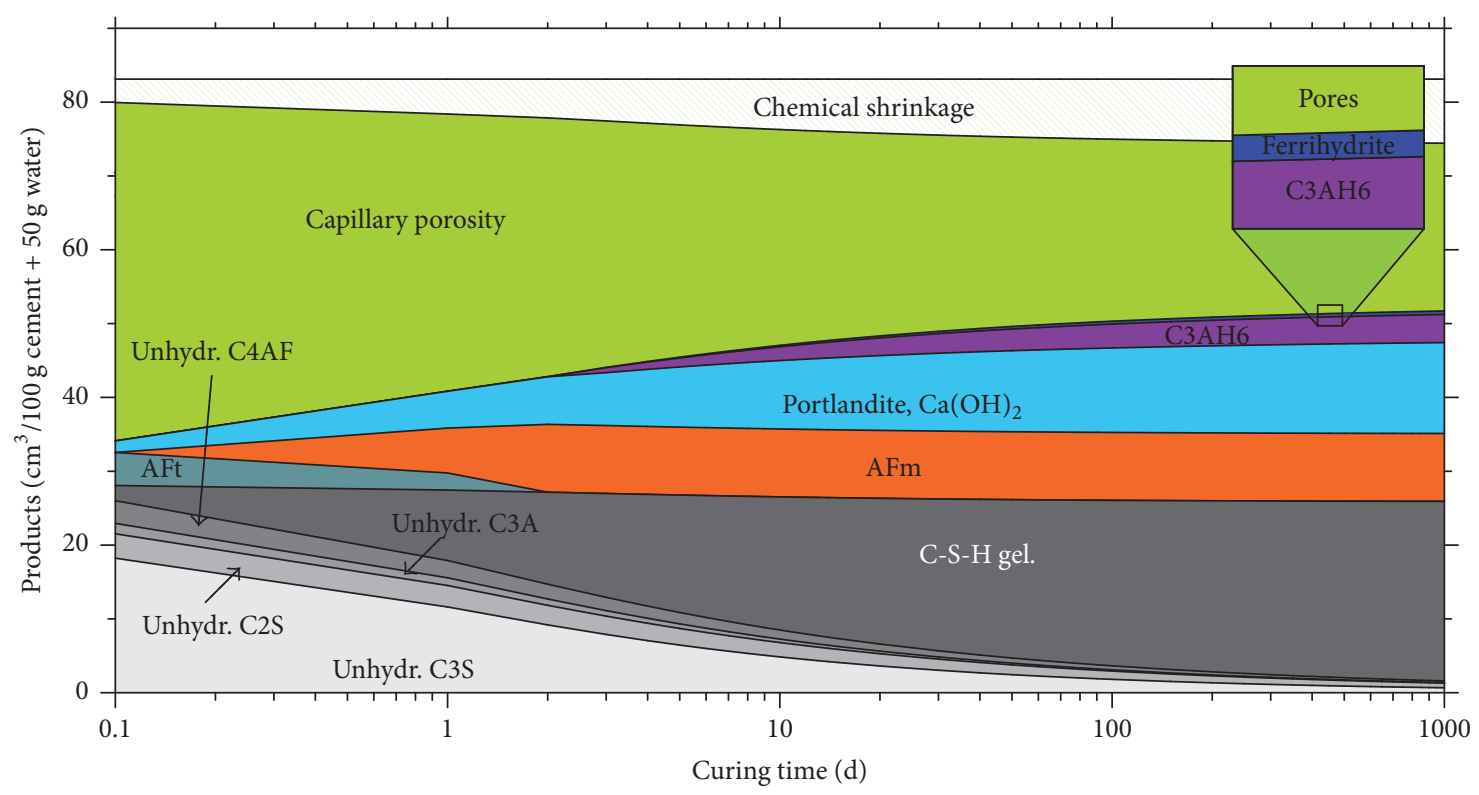

FIGURE 9: Hydrates evolution over curing time.

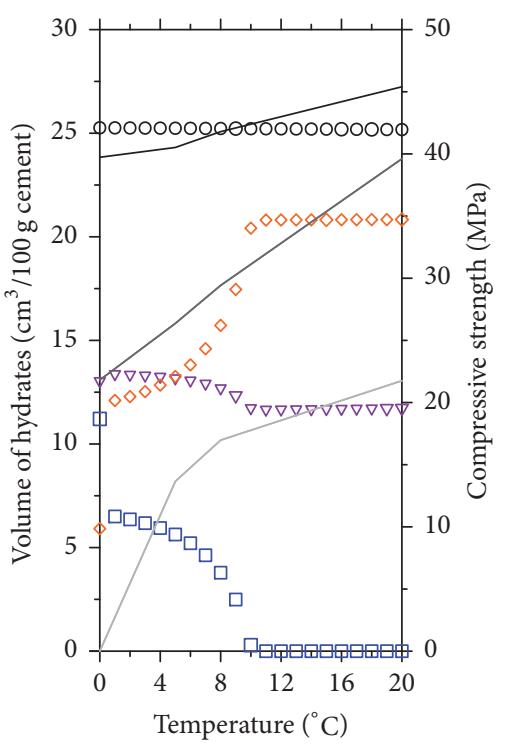

$\begin{array}{ll}\text { Hydrates } & \text { Strength } \\ \circ \diamond \circ \text { CSH } & -3 \mathrm{~d} \\ \square \square \square \text { AFt } & -7 \mathrm{~d} \\ \diamond \diamond \diamond \text { AFm } & -28 \mathrm{~d} \\ \nabla \nabla \nabla \text { Portlandite } & \end{array}$

FIGURE 10: Relationships between strength, hydrates, and temperature.

condition. Based on the CCR-II temperature sensors, the maturity might explain the hydration delaying.

(2) There was a linear relationship between DoH and curing temperature to $1-7 \mathrm{~d}$; however, a breakpoint appeared at 7-28d. In experiment, the breaking point appeared at $5 \sim 8^{\circ} \mathrm{C}$. This $\mathrm{DoH}$ breaking point is very similar to the phase transformation point in thermodynamics $\left(10^{\circ} \mathrm{C}\right)$.

(3) The calculation indicated that early mechanical behavior might have deeper explanations from the view of thermodynamics, where the hydrates differ under low temperatures. On the premise of this study (different early curing temperature), the compressive strength of old pastes ( $28 \mathrm{~d}$ ) has less relationship with the CSH content but is linked tightly with aluminate compounds and portlandite.

\section{Conflicts of Interest}

The authors declare that they have no conflicts of interest.

\section{Acknowledgments}

The authors would like to acknowledge the financial supports from the Natural Science Foundation of China (NSFC, no. 51708045) and the National Key Technology R\&D Program, China (2014BAG05B04), as well as address their thanks to graduate students Yongwei $\mathrm{Lu}$ and Wenxiu Jiao for their experiment assistant. They also appreciate the discussion and comments from experts in World Transport Convention (WTC, Beijing, 2017), where the data of this research was initially presented, partly. Laboratory experiments of this study were conducted in the Key Laboratory for Special Area Highway Engineering, MOE, China, and the Materials Analysis Center, School of Materials Science and Engineering, Chang'an University, and the Xian Mineral Resources Surveillance and Test Center, Ministry of Land and Resource of China. They gratefully acknowledge the support making these laboratories and their operation possible. 


\section{References}

[1] J. F. Young, S. Mindess, and D. Darwin, Concrete, Prentice Hall, New Jersey, NJ, USA, 2002.

[2] R. L. Kozikowski, W. C. McCall, and B. A. Suprenant, Cold Weather Concreting Strategies, edit by Rush Jr, W. E., 2014.

[3] B. Lothenbach, T. Matschei, G. Möschner, and F. P. Glasser, "Thermodynamic modelling of the effect of temperature on the hydration and porosity of Portland cement," Cement and Concrete Research, vol. 38, no. 1, pp. 1-18, 2008.

[4] Y. Qiao, H. Wang, L. Cai, W. Zhang, and B. Yang, "Influence of low temperature on dynamic behavior of concrete," Construction and Building Materials, vol. 115, pp. 214-220, 2016.

[5] L. Xu, P. Wang, and G. Zhang, "Formation of ettringite in Portland cement/calcium aluminate cement/calcium sulfate ternary system hydrates at lower temperatures," Construction and Building Materials, vol. 31, pp. 347-352, 2012.

[6] F. Karagol, R. Demirboga, and W. H. Khushefati, "Behavior of fresh and hardened concretes with antifreeze admixtures in deep-freeze low temperatures and exterior winter conditions," Construction and Building Materials, vol. 76, pp. 388-395, 2015.

[7] G. C. Lee, T. S. Shih, and K. C. Chang, "Mechanical properties of concrete at low temperature," Journal of Cold Regions Engineering, vol. 2, no. 1, pp. 13-24, 1988.

[8] T. Miura, "The properties of concrete at very low temperatures," Materials and Structures, vol. 22, no. 4, pp. 243-254, 1989.

[9] R. Demirboğa, F. Karagöl, R. Polat, and M. A. Kaygusuz, “The effects of urea on strength gaining of fresh concrete under the cold weather conditions," Construction and Building Materials, vol. 64, pp. 114-120, 2014.

[10] R. W. Nurse, "Steam curing of concrete," Magazine of Concrete Research, vol. 1, no. 2, pp. 79-88, 1949.

[11] A. G. Saul, "Principles underlying the steam curing of concrete at atmospheric pressure," Magazine of Concrete Research, vol. 2, no. 6, pp. 127-140, 1951.

[12] M. Maslehuddin, C. L. Page, and Rasheeduzzafar, "Temperature effect on the pore solution chemistry in contaminated cements," Magazine of Concrete Research, vol. 48, no. 5, pp. 5-14, 1997.

[13] ACI Committee, "Standard Specification for Cold Weather Concreting, (Reapproved 2002)," Tech. Rep. ACI 306.1-90, American Concrete Institute, Michigan, Mich, USA, 2010.

[14] ACI Committee, Guide to Cold Weather Concreting ACI 306R10, American Concrete Institute, Michigan, Mich, USA, 2010.

[15] J. Liu, Y. Li, P. Ouyang, and Y. Yang, "Hydration of the silica fume-Portland cement binary system at lower temperature," Construction and Building Materials, vol. 93, pp. 919-925, 2015.

[16] R. Polat, "The effect of antifreeze additives on fresh concrete subjected to freezing and thawing cycles," Cold Regions Science and Technology, vol. 127, pp. 10-17, 2016.

[17] Z. Liu, A. Sha, L. Hu, and X. Zou, "A laboratory study of Portland cement hydration under low temperatures," Road Materials and Pavement Design, vol. 18, no. sup3, pp. 12-22, 2017.

[18] Z. Liu, A. Sha, L. Hu et al., "Kinetic and thermodynamic modeling of Portland cement hydration at low temperatures," Chemical Papers, vol. 71, no. 4, pp. 741-751, 2017.

[19] L. Xiao and Z. Li, "New understanding of cement hydration mechanism through electrical resistivity measurement and microstructure investigations," Journal of Materials in Civil Engineering, vol. 21, no. 8, pp. 368-373, 2009.

[20] ASTM, Standard Practice for Mechanical Mixing of HydraulicCement Pastes and Mortars of Plastic Consistency C305-14,
ASTM International West Conshohocken, Philadelphia, Pennsylvania, Pa, USA, 2014.

[21] J. J. Beaudoin, P. Gu, J. Marchand, B. Tamtsia, R. E. Myers, and Z. Liu, "Solvent replacement studies of hydrated portland cement systems: the role of calcium hydroxide," Advanced Cement Based Materials, vol. 8, no. 2, pp. 56-65, 1998.

[22] T. C. Powers and T. L. Brownyard, "Studies of the physical properties of hardened Portland cement paste," Journal of the American Concrete Institute, 1946.

[23] K. D. Smith, Maturity Testing for Concrete Pavement Applications, 2005.

[24] L. J. Parrot and D. C. Killoh, "Prediction of cement hydration," Proceedings of the British Ceramic Society, p. 41, 1984.

[25] F. Lin and C. Meyer, "Hydration kinetics modeling of Portland cement considering the effects of curing temperature and applied pressure," Cement and Concrete Research, vol. 39, no. 4, pp. 255-265, 2009.

[26] H. F. W. Taylor, Cement Chemistry, Thomas Telford Publishing, London, UK, 2nd edition, 1997.

[27] F. Tomosawa, "Development of a kinetic model for hydration of cement," in Proceedings of the 10th Interenational Congress on the Chemistry of Cement, p. 5158, 1997. 

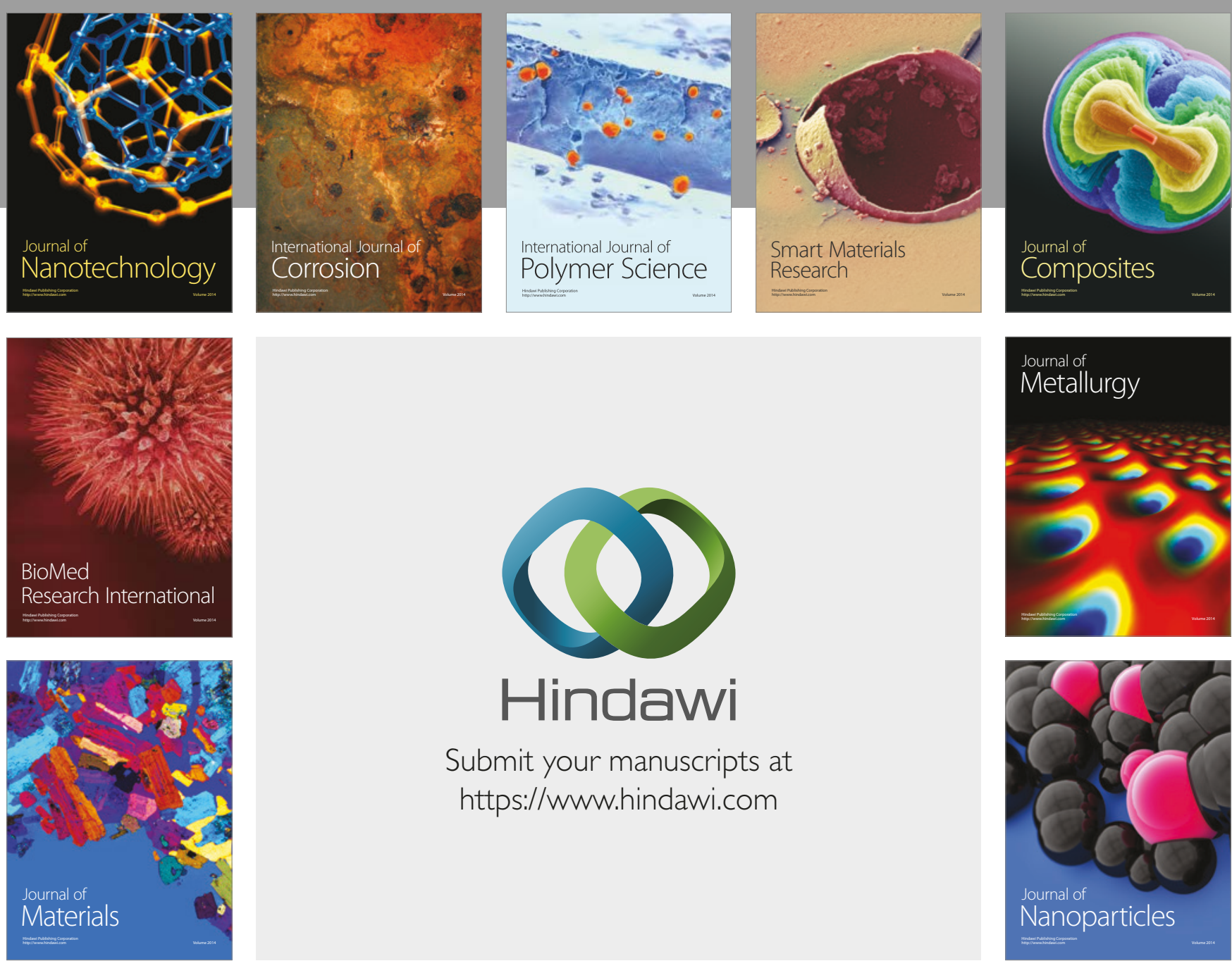

\section{Hindawi}

Submit your manuscripts at

https://www.hindawi.com
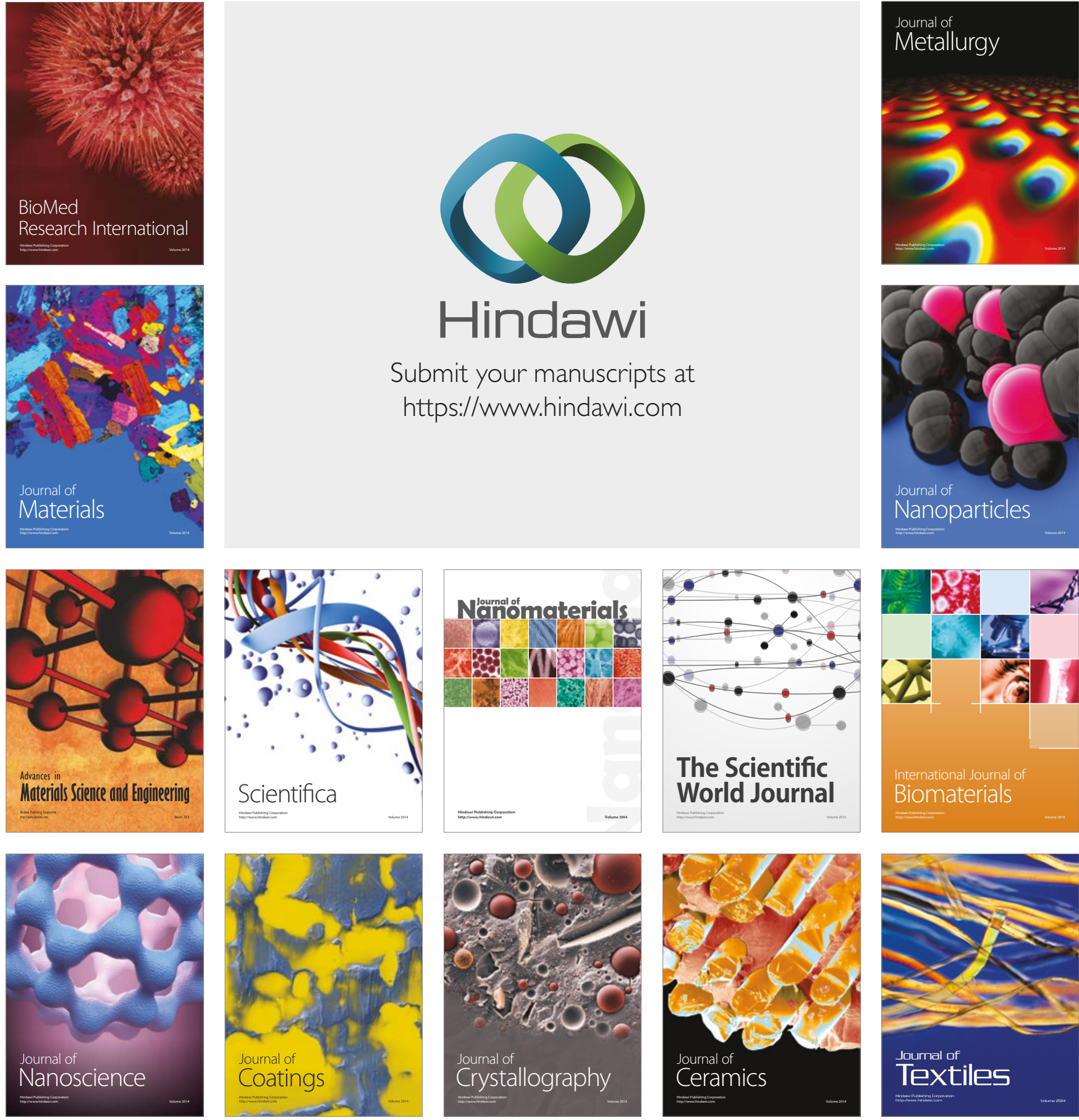

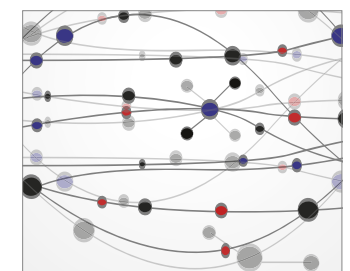

The Scientific World Journal
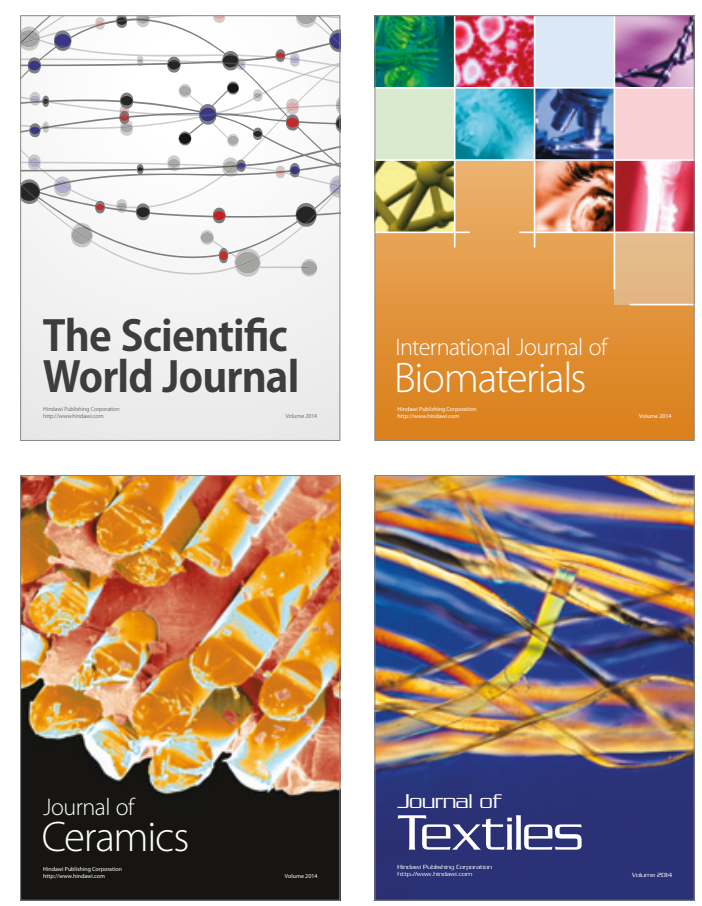